\title{
CAMBIOS DE CONSUMO Y DE GUSTO DE LOS VINOS DE JEREZ EN EL REINO UNIDO Y SUS CONSECUENCIAS EN LA ZONA DE PRODUCCIÓN ENTRE MEDIADOS DE LOS SIGLOS XVIII Y XIX
}

\author{
CHANGES IN THE CONSUMPTION OF SHERRIES AND \\ THE TASTE FOR THEM IN THE UNITED KINGDOM \\ AND THEIR CONSEQUENCES IN THE AREA \\ OF PRODUCTION BETWEEN THE MID-EIGHTEENTH \\ AND THE MID-NINETEENTH CENTURIES
}

\author{
Javier Maldonado Rosso \\ Universidad de Cádiz
}

Entregado el 18-7-2012 y aceptado el 3-11-2012.

Resumen: La demanda de vinos Jerez en el Reino Unido (su principal mercado) mudó de tendencia en dos ocasiones durante los siglos XVIII y XIX y en ambas propició importantes transformaciones económicas y técnicas que conformaron la agroindustria vinatera jerezana contemporánea. Por su parte, las características y causas de esos cambios de mudanza sólo pueden entendidos sobre la consideración de que gusto y consumo son dos factores diferentes, aunque relacionados, y de que, como pone de manifiesto la correspondencia comercial entre casas exportadoras jerezanas y sus agentes comerciales en el Reino Unido, el mercado británico de vinos era muy complejo en ese periodo.

Palabras clave: agroindustria, comercio de vinos, España, Jerez, Reino Unido.

\footnotetext{
Abstract: The demand for sherries in the United Kingdom (its main market) changed its tendency on two occasions during the eighteenth and the nineteenth centuries, bringing about on both of them significant economic and technical
} 
transformations which shaped contemporary wine agro-industry in the Jerez district. For their part, the features and causes of those changes in tendency can only be understood on the basis of a consideration: that taste and consumption are two different, but related, factors; and that the British wine market was very complex in that period, as evidenced by the business letters between the shipping houses in Jerez and their commercial agents in the United Kingdom.

Key words: agro-industry, wine trade, Spain, Jerez, United Kingdom. 
Durante la mayor parte de los siglos XVIII y XIX, el jerez fue uno de los vinos más consumidos en el Reino Unido, junto con el oporto, el burdeos $y$, en menor medida, el Madeira, el marsala y el canarias ${ }^{1}$. Esta preferencia se explica porque se adaptaba al gusto de los consumidores británicos, así como por el hecho de haber sido favorecido por la caída de las importaciones de vino de Burdeos a consecuencia de prohibiciones y altos aranceles impuestos a las mercancías francesas a partir de los años setenta del siglo XVII. Se tiene la idea de que el jerez de ese periodo era un vino de alta graduación alcohólica (obtenida mediante fortificación con aguardiente vínico), paladar abocado (conseguido con mezclas de diferentes vinos secos y dulces) y color oscuro (logrado por envejecimiento y/o por adición de vino color), que resultaría ser lo que los británicos denominaban Sherry Brown. Pero, la realidad era más compleja. Nos proponemos analizar los cambios de consumo y de gusto de los consumidores británicos respecto al vino de Jerez entre mediados de los siglos XVIII y XIX, sobre la base de la correspondencia comercial entre las casas exportadoras jerezanas y sus agentes comerciales en el Reino Unido, así como sus posibles causas y las notables consecuencias que tuvieron en la zona de producción.

\section{La revolución inglesa de las bebidas y el jerez contemporáneo}

El jerez contemporáneo surgió con el primer gran cambio de gusto respecto al vino acaecido en el Reino Unido, denominado la revolución inglesa de las bebidas, que tuvo lugar entre los años sesenta del si-

${ }^{1}$ Cyrus Redding, A History and Description of Modern Wines, Henry G. Boiin, London, 1851, pp. 395; André L. Simon, Bottlescrew days. Wine drinking in England during the $18^{\text {th }}$ century, Duckworth, London, 1926, pp.; Ralph Davis, «The english wine trade in the eighteenth and nineteenth centuries», Annales Cisalpines d'Histoire Sociale, serie I, n. ${ }^{\circ} 3$, 1972, pp. 87-106, pp. 88-89; A. D. Francis, The Wine Trade, Adam and Charles Block, London, 1974, pp. 320-325; James Simpson, «La producción de vinos en Jerez de la Frontera, 1850-1900», en P. Martín Aceña y L. Prados de la Escosura (Eds.), La nueva historia económica en España, Tecnos, Madrid, 1985, pp. 166-191; Juan Pan-Montojo, La bodega del mundo. La vid y el vino en España (1800-1936), Alianza Universidad, Madrid, 1994, pp. 103-105: Diego Téllez Alarcia, «El comercio de vino español con Inglaterra a mediados del siglo XVIII. Un proyecto político», Brocar, n. ${ }^{\circ} 29$, 2005, pp. 77-89, p. 81; James Simpson, «The British Marker and the International Wine Trade: The Limits to Export-Led Growth befote 1914», en Homenaje a Gabriel Tortella, edt. José Morilla et alii, Universidad de Alcalá de Henares, 2010; y James Simpson, Creating Wine. The emergente of a World Industry, 1840-1914, Princenton University Press, 2012. 
glo XVII y las primeras décadas del XVIII. Consistió en un auge del consumo de «nuevas» bebidas (café, chocolate, ron, ginebra...) y en la preferencia por vinos de alta graduación alcohólica, con cuerpo, y de color oscuro; en oposición a los vinos ligeros, claros y de poca graduación, que eran los más extendidos hasta entonces. Se atribuye este cambio de gusto a la caída de las importaciones de vino de Burdeos (French Claret) que produjo la prohibición, primero, entre 1678 y 1686 , y el alto arancel, después, a partir de 1689, que impuso el gobierno británico a las mercancías de Francia, en razón de la guerra que mantuvieron entre sí ambas potencias por la hegemonía en el Atlántico. El «desabastecimiento» de vino de Burdeos propició el incremento de las importaciones británicas de vinos de Oporto, principalmente, y Jerez y habría dado lugar a la elaboración en Francia de un burdeos de mayor calidad y de características organolépticas diferentes a la del French Claret: esto es, a un vino tinto propiamente dicho (no un clarete), de color oscuro, mayor graduación alcohólica, más cuerpo y sabor más intenso. Este New French Claret habría sido una iniciativa de los comerciantes británicos de vinos establecidos en la zona de Burdeos tendente a mantener su actividad mediante un vino de calidad cuyo precio permitiera hacer frente al altísimo arancel establecido en el Reino Unido a los vinos franceses y que generase beneficios ${ }^{2}$.

Consideramos que es preciso atender al hecho de que los nuevos vinos franceses de calidad comenzaron a elaborarse antes del inicio de las guerras franco-británica de 1672 a 1697, aunque el desarrollo de sus características fue un proceso que duró aún algunas décadas. En 1666, el empresario francés Arnaud de Pontac, propietario del viñedo Haut-Brion, en la zona de Les Graves, abrió en Londres un restaurante de lujo en el que ofrecía un nuevo vino de Burdeos, parecido al New French Claret, denominado en el Reino Unido Ho Bryan ${ }^{3}$. A este

${ }^{2}$ Henry Enjalbert, «Comment naissent les grands crus. Bordeaux, Porto, Cognac», Annales, Economies, Sociétés, Civilisations, n. ${ }^{\circ} 3$, 1953, pp. 315-328 y n. ${ }^{\circ} 4,1953$, pp. 457-474, y Histoire de la Vigne et du Vin, Bordas, Paris, 1975, pp. 81-118; Pierre Butel, «Grands proprietarirescet production des vins du Médoc au XviIe siècle», Revue Histórique de Bordeaux, T. 12, n. ${ }^{\circ} 2$, pp. 129-141; René Pijassou, «Le marché de Londres et la naissance de grands crus médocains (Fin XVIIe siècle-début XVIII siècle)», Revue Histórique de Boordeaux, . $^{\circ} \mathrm{xxx}, 1974$, pp 139-150; René Pijassou, «Les conditions históriques et geographiques de la naissance des grands crus au XVIIIe siècle», en 3e Symposium Internationale d'Oenologie, IRRA, 1987, pp. 3-13.

${ }^{3}$ Henri Enjalbert, Histoire de la Vigne..., pp. 97-98. 
hecho tan significativo se une la constatación de que en 1660 era ya conocido el champán espumoso, una innovación cualitativa de los vinos de la Champagne ${ }^{4}$. Es probable que estos antecedentes no hayan sido tenidos en cuenta suficientemente en la explicación de este cambio de gustos respecto al vino operado en el mercado británico. El impacto de las medidas arancelarias británicas sobre las importaciones de vinos franceses y la consiguiente sustitución por vinos portugueses y españoles para satisfacer la demanda de tal producto es un hecho incuestionable y de evidente importancia en el consumo de vinos en este país, pero no se operó inmediatamente, pues, como Fisher ha constatado, el aumento de las importaciones de vinos portugueses al Reino Unido entre los años 1679 y 1685 consistió mayoritariamente en vinos franceses falsamente identificados 5 .

La aparente contradicción que planteamos sólo puede resolverse si distinguimos dos aspectos diferentes, aunque sin duda relacionados: gusto y consumo. En condiciones favorables, el consumo se corresponde con el gusto; en cambio, en condiciones desfavorables, el gusto tiene que ser sacrificado en función de las posibilidades de consumo. Sobre esta base es posible comprender que lo que sucedió en el Reino Unido a partir de los años sesenta del siglo XVII fue la coincidencia de dos procesos diferentes: el cambio de gusto por los nuevos vinos de calidad, que se inserta en la acertadamente denominada revolución inglesa de las bebidas, y el cambio en el consumo de vinos en detrimento de los franceses y a favor de los portugueses y españoles, que obedece al alto arancel que a partir de 1689 gravaba los vinos franceses.

La causa de la revolución inglesa de las bebidas y, especialmente, del cambio de gusto por vinos de calidad se debió a un aumento de la demanda y de la oferta como consecuencia de la mejora del nivel de vida, el desarrollo demográfico y el crecimiento de la población urbana en el Reino Unido y otros países norte-europeos. Como se ha señalado, el cambio de gusto por los vinos de calidad tuvo mucho que ver con la posibilidad de las clases acomodadas de acceder a productos de altos precios y su tendencia a establecer símbolos de distinción social ${ }^{6}$. Los sectores

${ }^{4}$ André L. Simon, The history of Champagne, Ebury, London, 1962, p. 49.

5 H. E. S. Fisher, De Methuen a Pombal. O Comércio Anglo-Português de 1700 a 1770, Gradiva, Lisboa, 1971, pp. 46-49.

${ }^{6}$ Marcel Lachiver, Vins, vignes et vignerons. Histoire du vignoble français, Fayard, Lille, 1988, p. 330; y Pierre Bourdieu, La distinción. Criterio y bases sociales del gusto, Taurus-Santillana Ediciones, S.L., Madrid, 2012, pp. 207-210 y 441-443. 
más pudientes de la sociedad británica pudieron disfrutar del nuevo burdeos pese a su elevado precio.

Parece lógico que un simple cambio de consumo de vino por causas exclusivamente arancelarias habría consistido en la sustitución de los claretes franceses por claretes o tintos jóvenes portugueses y españoles. Sin embargo, el cambio en el consumo se asoció al cambio de gusto por vinos de mayor graduación alcohólica, más cuerpo y color. Y fue por ello, así como por el conocimiento que se tenía en el mercado británico de los vinos de Oporto y Jerez, y por interés de los comerciantes británicos de vinos, por lo que el clarete francés fue sustituido por vinos de muy diferente clase, como el oporto y el jerez. No obstante lo dicho, hay que matizar que el cambio de gusto por vinos de calidad no fue un fenómeno que tuviese lugar con rapidez, sino que se trató de un proceso que se extendió durante varias décadas.

\section{Tipos de vinos de Jerez y su evolución}

El nuevo jerez al gusto del mercado británico, surgido de la revolución inglesa de las bebidas (pero desarrollado con retraso en la zona, a partir de mediados del siglo XVIII, debido a la obstrucción de los grandes cosecheros jerezanos), consistía en realidad en una pluralidad de tipos de vinos: secos, tiernos o abocados, y dulces. Se trataba de vinos compuestos o vinos de exportación, esto es, preparados al efecto para los consumidores británicos. Estos tipos se elaboraban a partir de un vino de determinada vejez absoluta (si era criado por el sistema de añadas) o vejez media (si era criado por el sistema de soleras), al que se añadía vino Color, vino dulce y aguardiente vínico, según las características solicitadas por los clientes. Algunos de estos vinos eran cabeceados (combinados) también con vinos viejos que se empleaban como vinos madres o de solera, a fin de mejorar su calidad ${ }^{7}$.

El desarrollo del sistema de crianza mediante criaderas y soleras y el predominio de la variedad de vid Palomino o Listán (más temprana y esquilmeña), que fue sustituyendo el elevado número de castas de vid que

7 Javier Maldonado Rosso, La formación del capitalismo en el Marco del Jerez. De la vitivinicultura tradidicional a la agroindustria vinatera moderna (siglos XVIII y XIX), Huerga y Fierro Editores, Madrid, 1999, pp. 175-181. 
se cultivaban hasta finales del siglo XVIII en la zona, condujeron a notables cambios en la elaboración y los tipos de vinos de Jerez ${ }^{8}$.

Aunque su existencia data de mediados del siglo XVIII, desde comienzos de la siguiente centuria el sistema de soleras fue desarrollándose y definiéndose. Este sistema consiste en la combinación ininterrumpida de vinos nuevos de cada cosecha con vinos más viejos de cosechas anteriores, mediante la corrida de escalas en las llamadas criaderas. La solera es la última de las escalas, de donde se saca el vino para su venta. Dependiendo de la cantidad y frecuencia de las sacas, el vino de las soleras mantiene una vejez media. Este sistema hace más rápido el proceso de envejecimiento y consigue la homogeneidad de los tipos de vinos naturales de Jerez con independencia de la calidad de cada cosecha. Los vinos de añada fueron siendo sustituidos por los de solera en un paulatino proceso. En estos años de las primeras décadas del siglo XIX ya se distinguían soleras finas, olorosas ${ }^{9}$, etc.

El jerez natural joven es un vino fortalecido con alcohol vínico, de color pálido, cuerpo ligero y sabor seco, que adquiere unos colores dorado y ámbar con el envejecimiento; a excepción del tipo denominado Fino, que permanece pálido, pese a ser envejecido, debido a su crianza biológica, que consiste, grosso modo, en que el velo de flor que forman espontáneamente las levaduras en su superficie en el interior de los toneles impide su oxidación. Según el proceso de crianza elegido se elaboran tres tipos básicos de vino de Jerez seco: Fino, Amontillado y Oloroso, cuyos respectivos colores son pálido, dorado y ámbar. Para obtener vino Fino, el vino joven, se encabezaba con alcohol vínico hasta 15,5 grados, si no obtenía tal graduación de manera natural, y se sometía a crianza biológica. Para obtener el tipo Oloroso se encabeza el vino joven hasta 17 ó 18 grados, concentración alcohólica en la que las levaduras no pueden desarrollarse, por lo que no se forma velo de flor, y el vino, en contacto directo con el oxigeno del aire, se va oxidando durante su envejecimiento físico-químico y adquiere el color ámbar. El Amontillado es un tipo de vino que envejece por crianza biológica durante unos años y por crianza físico-química u oxidativa durante otros años. Es vino Fino al que se deja que pierda el velo de flor paulatinamente o bien se le encabeza con alcohol vínico hasta $16 \mathrm{o}$

${ }^{8}$ Simón de Roxas Clemente y Rubio, Ensayo sobre las variedades de vid común que vegetan en Andalucía, Imprenta de Villalpando, Madrid, 1807, p. 135; y Javier Maldonado Rosso, op. cit., pp. 159-161.

9 Javier Maldonado Rosso, op. cit., pp. 163-171. 
17 grados, concentración en la que el velo de flor se pierde por resultar un medio inhabitable para las levaduras. Durante la criaza oxidativa, el vino va adquiriendo color dorado; si se le deja envejecer muchos años llega a tomar color ámbar. Conviene precisar que no se trata de una imitación del vino de Montilla, sino que es un vino de Jerez natural parecido al de de esa localidad cordobesa, en la que debido a su alta temperatura y baja humedad relativa el velo de flor se perdía en verano y el vino se oxidaba, razón por la cual no se producía en el siglo XIX el tipo Fino, sino el llamado Montilla. En la zona de Jerez al vino parecido al de Montilla se le dio el nombre de Amontillado. Un cuarto tipo de vino de Jerez seco natural es el Palo Cortado, que tiene aroma de Amontillado y paladar de Oloroso: es una rareza enológica de mucha complejidad y calidad.

Estos tipos naturales de vino de Jerez no se exportaban para el Reino Unido en la primera mitad del siglo XIX salvo de manera excepcional. El vino Fino se comenzó a criar en la primera o segunda década del siglo XIX, pues hasta 1801, al menos, se consideraba que el velo de flor era perjudicial y se le quitaba ${ }^{10}$. Los vinos de exportación continuaron siendo mezclas (cabeceos) de estos vinos secos entre sí y/o con vino dulce, de diferentes edades; y según el tipo y el gusto de los consumidores se les adicionaba diferente proporción del llamado vino Color y se reencabezaban - refortalecían- con alcohol vínico cuando se preparaban para la exportación ${ }^{11}$.

La clasificación de los vinos de exportación de Jerez hasta la segunda mitad del siglo XIX era numérica, pues estaba establecida en relación a la edad, que era el criterio de calidad para los vinos envejecidos. La gama comprendía vinos de los números 1 al 10, aunque los más vendidos eran los números 1 al 6. En el año 1827, la casa exportadora CZ describía de la siguiente manera algunos de sus vinos: $\mathrm{N}^{\circ} 1$, vino trasañejo; $\mathrm{N} .^{\circ} 2$, vino superior reañejo; $\mathrm{N}^{\circ} 3$, vino superior y bien reañejo; y $\mathrm{N} .{ }^{\circ} 7$, vino más superior y bien reañejo. Se trata de una descripción muy imprecisa, puesto que los calificativos superior, más superior y bien reañejo no aportan información significativa. Duff Gordon indicaba en 1834 las edades de sus vinos $\mathrm{N}^{\circ}{ }^{\circ} 0,1,4$ y 6 , que tenían, respectivamente, tres, cuatro, seis

10 Javier Maldonado Rosso, «En torno a los comienzos del Fino como tipo de vino diferenciado», en Javier Maldonado Rosso (ed.): Actas de las I Jornadas del Vino Fino, Ayuntamiento de El Puerto de Santa María, 1996, pp. 31-60, pp. 47-48

${ }_{11}$ André L. Simon, Bottlescrew days..., pp. 51, 55-57 y 109-110; Julian Jeffs, El vino de Jerez, Universidad de Cádiz, Cádiz, 1994, p. 361; y Javier Maldonado Rosso, La formación del capitalismo..., pp. 50-51. 
u ocho, y diez años de vejez. No parece que esta equivalencia sea la que se empleó desde la segunda mitad del siglo XVIII hasta los años veinte del siglo XIX, periodo en el que, de acuerdo con lo señalado por el exportador Juan Haurie, el N. 1 era un vino de dos a tres años de envejecimiento, como máximo. Cada uno de estos tipos numéricos podía ser de color pálido, oro o ámbar y podía ser seco, semiseco, semidulce o dulce. Así, se pedían vinos de diferentes números (de distintas edades) pero con las mismas características organolépticas de paladar, cuerpo y color ${ }^{12}$.

Pero esta variedad no se limitaba a la ya amplia gama de tipos de vinos que ofrecían los productores, sino que se ampliaba ad infinitum mediante la posibilidad que tenían los comitentes de hacer pedidos singulares: más o menos cargado de aguardiente, especificidades de cuerpo (fino, hecho, gordo...), de tonalidades de los colores básicos, y de paladares (seco, no muy seco, muy seco, suave, rico, almendrado...). Las casas exportadoras jerezanas se quejaban a sus agentes de que algunos comitentes no sabían indicar con exactitud los tipos de vinos que deseaban, pero la crítica generalizada consistía en que el mercado británico era muy variado y caprichoso. Al respecto era muy elocuente Francisco-Antonio de la Tijera, de la casa exportadora CZ, que en 1803 decía que era muy difícil o tan imposible uniformarse en el gusto para agradar completamente a los Hombres, y particularmente a los Ingleses en orden a vinos que pocas veces se dan por contentos $^{13}$. A esas críticas de las casas exportadoras a sus agentes en el Reino Unido, estos respondían reconociendo la complejidad del mercado británico de vinos. Sandeman le contestó en este sentido a Pemartin en 1827 que transmitían lo que a sus socios les decían los comitentes en sus viajes periódicos por el país, a fin de que les sirviese a ellos de gobierno para la preparación de los vinos, pero se exculpaba diciendo: nunca podremos explicar si las diferencias de paladar y la preferencia que dan a un vino o a otro estan bien fundadas o son fantasias ${ }^{14}$. Aunque el mercado británico de vinos era muy diverso, parece ser que hasta las primeras décadas del siglo XIX los tipos de jerez más demandado fueron los denominados Sherry Golden (vino de color dorado, cuerpo consistente, alta graduación alcohólica y paladar semiseco o semidulce) y Sherry Brown (de color ámbar, cuerpo hecho, alta graduación alcohólica y paladar semiseco o semidulce).

12 Javier Maldonado Rosso, La formación del capitalismo..., pp. 177-181.

13 Ibidem, p. 180.

14 Archivo Histórico Sandeman Jerez (en adelante A.H.S.J.): Correspondencia Comercial, Londres, 18-XII-1827. 


\section{El cambio de tendencia hacia el jerez pálido}

Es sabido que en el siglo XIX los consumidores británicos comenzaron a mostrar su preferencia por los vinos de Jerez pálidos y finos, pero no hay acuerdo sobre cuándo se dio este cambio de tendencia, que se viene situando en los años setenta, sesenta o cincuenta, como pronto, según referencias de época y diferentes autores ${ }^{15}$. Una cuestión esencial, que desarrollaremos más adelante pero que es preciso adelantar ya, es que los vinos pálidos y el vino Fino (cuyo color es pálido) eran en el siglo XIX dos tipos diferentes de vinos de Jerez.

En el que es el primer estudio científico de la historiografía reciente sobre la vitivinicultura jerezana contemporánea, James Simpson señala que el incremento de la demanda del jerez Fino en el mercado británico a partir de la década de los años sesenta del siglo XIX estuvo asociado a la degradación de calidad de los jereces más añejos y dulces y al cambio de gusto operado desde mediados de esa centuria a favor de vinos más ligeros y $\operatorname{secos}^{16}$. Simpson se basa en lo que se refiere al incremento del jerez Fino en la fecha de 1858 que da González Álvarez como cambio de tendencia ${ }^{17}$. Esta afirmación es correcta para el vino Fino, pero no lo es para los vinos pálidos, como veremos. Otras fuentes no son tan precisas y no distinguen pálidos de finos.

Para tratar de conocer lo sucedido hemos recurrido a la correspondencia comercial entre varias casas exportadoras de la zona del jerez y sus agentes distribuidores en el Reino Unido, por considerar que es una de las fuentes documentales más ricas en información cualitativa y más fiables al respecto. Se trata de las casas exportadoras Duff Gordon, establecida en El Puerto de Santa María, y de Julián Pemartin y C. a, Pedro Domecq, y CZ, establecidas en Jerez. Todas ellas estaban entre las más importantes del sector en volumen de ventas y reputación de calidad. El estudio de esta correspondencia comercial pone de manifiesto que al menos desde principios de los años veinte del siglo XIX los vinos pálidos de la zona del

15 Julian Jeffs, op. cit., pp. 139-140; James Simpson, «La producción de...», p. 170, cita lo que decía al respecto Denman en 1876.

16 James Simpson, «La producción de... , p. 170.

${ }^{17}$ Francisco Gónzález Álvarez, Apuntes sobre los vinos españoles, Librería de Cuesta, Madrid, 1878, pp. 44-45. Juan Pan-Montojo, op. cit., p. 104, señala que no le parece lógico que se dé una datación tan precisa, como hace González Álvarez, para un cambio de esta índole. 
jerez comenzaban a estar de moda en el mercado británico. O sea, tres décadas antes de lo que se había considerado hasta ahora, el jerez pálido era ya un tipo de vino que gozaba de las preferencias de los consumidores de algunas zonas del Reino Unido, y esa tendencia fue extendiéndose a lo largo de la citada década: en octubre de 1826, el comerciante inglés J.C. Parker decía que él podría vender una gran cantidad de vinos como los de una hermosa muestra de Pale Sherry al precio de 22 y 26 libras, embarcada por la casa jerezana Juan Haurie y Sobrinos, que había tenido la oportunidad de $\operatorname{ver}^{18}$. Al año siguiente, 1827, se comenzaron a apreciar los vinos pálidos en Newcastle, según le indicaba George Sandeman a Julián Pemartin y C. ${ }^{\text {a }}$, de cuya empresa fue agente hasta la década de los setenta de esa centuria ${ }^{19}$. Esta tendencia por los vinos pálidos continuó en las siguientes, pero hay que precisar también que no sólo prosiguió el consumo de otros tipos de jereces (golden y brown), sino que había confusiones acerca de qué se consideraba vino pálido.

De los vinos de color oscuro decía Sandeman en 1829 que tenían bastante consumo en esta y otras partes, refiriéndose a Londres y otras zonas del Reino Unido ${ }^{20}$. Sin embargo, en 1830, el comerciante James. B. Bollard, de Cork, hizo un pedido de vino de lo mas palido para mezclar con otros muy cargados que tiene, y que no ha podido vender por ser tan subido su color ${ }^{21}$. Pemartin, enterado de que en Newcastle gustaba más el jerez color oro por tener más cuerpo que el pálido, dejó de embarcar este tipo de vino a la citada ciudad en 1829, sólo dos años después de que se le hubiese dicho que principiaban a tener preferencia entre los consumidores de ella ${ }^{22}$. En esta misma línea, el establecimiento comercial Monkhouse se quejó en 1830 de unos vinos pálidos que había recibido, que despachaban mezclados con los de Gordon que tienen mas cuerpo y color $^{23}$. Estas y otras muchas referencias, que pueden parecer contradictorias, son manifestaciones de la complejidad del mercado británico de vi$\operatorname{nos}^{24}$. Con ellas queremos subrayar que no es que a partir de finales de los

18 A.H.S.J.: Correspondencia Comercial, Londres, 31-X-1826.

19 Ibidem, 25-X-1827

${ }^{20}$ Ibidem, 4-XII-1829

21 Ibidem, 2-VII-1830

22 Ibidem, 10-IV-1829.

23 Ibibem, 21-V-1830.

${ }^{24}$ Gaspar Martins Pereira, «A evoluçâo das técnicas vitivinicolas no Douro oitocentista», en Os vihnos licorosos e a história, CEHA, Funchal, 1998, pp. 225-237, p. 228, califica de contradictorias las demandas de vino de Oporto por parte del mercado británico. 
años veinte se recuperase el gusto por los vinos de más color, cuerpo y sabor, sino que este paladar se mantenía y que el mercado era muy variable por zonas y por periodos, así como por las características sociales de los consumidores y su poder adquisitivo.

Respecto a qué se consideraba vino pálido, Pemartin trataba de aclarar con Sandeman esta cuestión en 1826: Para entendernos llamaremos este color, blanco, y palido el que hemos acostumbrado a enviar a esa del $n .^{\circ} 1$ en adelante $^{25}$. Pero al año siguiente se veía en la necesidad de pedir que le diesen idea mas exacta de los vinos pálidos, ligeros y de buen paladar que Gooden, socio de Sandeman, quería recibir ${ }^{26}$. La incertidumbre era mayor, si cabe, en julio de 1830, fecha en la que Pemartin le escribe a Sandeman: Nos solemos quedar en duda con la denominación palido que dan igualmente a vinos que lo son mas o menos, y para evitar equivocaciones les estimaremos designen con el nombre de blanco el que se paresca a la muestra de libras 40 que nos mandaron últimamente y de palido el que deba ir como el de vms, pues el de Yrlanda y algunos otros puntos va mas cargado de color ${ }^{27}$.

Las descripciones señaladas dan información sobre el color y el cuerpo, pero no sobre el sabor del Pale Sherry, que es la principal característica organoléptica de los vinos. Que se trataba de una novedad queda claro en lo que le decía Agustín Ribaupierre a Juan-Nicolás Bölh de Faber, ambos de la casa Duff Gordon, en 1823: El que aquí en Londres califiquen de gusto a nuevo lo que vms. llaman allá fino, es propiamente cuestión de nombre ${ }^{28}$. Esta información apunta a que se trataría de un vino de paladar seco, dado que hace referencia a vino fino y señala que es un gusto nuevo, pero conviene comprobar esto. Hay una confusión, muy extendida en algunas zonas y países, consistente en asociar en los vinos el color pálido con el sabor seco. Pero esto no es así siempre: hay vinos pálidos que son dulces, como los célebres tokay y sauternes; y hay vinos blancos de mesa semidulces. La denominación de origen Jerez-Xèrés-Sherry ampara desde hace años el tipo Sherry Pale Cream, que es un vino de color pálido y sabor semidulce, cuyos orígenes están en la primera mitad el siglo XIX. ¿Cuál era, pues, el sabor que tenía el jerez pálido que se consu-

25 A.H.S.J.: Copiador de Cartas A, Jerez, 14-XI-1826.

26 Ibidem, 27-XI-1827.

27 A.H.S.J.: Copiador de Cartas B, 6-VII-1830.

28 Archivo Histórico Osborne y C. ${ }^{\text {a }}$ (en adelante A.H.O.C. $\left.{ }^{\mathrm{a}}\right)$.: Correspondencia Comercial, legajo 125, Londres, 9-XII-1823. 
mía en el Reino Unido a partir de la segunda década del siglo XIX? En realidad, hay que hablar de sabores del vino pálido de Jerez en ese periodo.

El Pale Sherry que tomaba la preferencia de los consumidores británicos desde la segunda y tercera décadas del siglo XIX se comercializaba en cuatro sabores: muy seco, seco, semiseco y semidulce, que se preparaban según el gusto de cada zona y de las variaciones que deseaban los clientes. En la década de los setenta del siglo XIX, una bota de 500 litros de un Pale Sherry estándar estaba compuesta por un 50\% de vino pálido, un $40 \%$ de vino Fino, un 7,5\% de vino dulce y un 2,5\% de aguardiente vínico ${ }^{29}$. Es muy probable que la composición de los vinos pálidos décadas atrás fuese muy similar a ésta, con la salvedad de que cabían otras muchas variantes, según apeteciesen los clientes de diferentes zonas del Reino Unido, que, como ya hemos tratado, pedían que se preparasen los vinos a su gusto particular. Además de vinos pálidos de exportación, también se embarcaban algunos vinos pálidos naturales.

De esos cuatro paladares, los tipos más consumidos de pálido parece que fueron el seco y el semiseco, según consta en la correspondencia comercial y señalaron algunos expertos británicos en vinos que visitaron la zona de Jerez y escribieron sobre el particular. Uno de los más documentados y entendidos, Henry Vizetelly, decía en los años setenta que los vinos de Jerez llevaban algo de vino dulce por considerarse demasiado secos para los gustos ingleses, ya que al ser punzantes les daba un sabor desagradable ${ }^{30}$. En ese mismo sentido iban las notas de los comitentes británicos de las casas exportadoras jerezanas, que a veces se quejaban de que recibían vinos demasiado pálidos y secos y rechazaban el vino Amontillado, pues como le decían en 1824 desde la sede londinense de Duff Gordon a Juan-Nicolás Bölh de Faber, su gerente en El Puerto de Santa María, no sirve el amontillado como elemento de vino superior [...] es un gusto seco que no place en el paladar, en lugar de aquel unto y cuerpo que se hallaba en los anteriores ${ }^{31}$. También se lamentaba en 1825 Julián Pemartin, dirigiéndose a Sandeman, de que se hubiese perdido el gusto por el Amontillado en Londres ${ }^{32}$. Y es muy significativo que en 1831 hubiese quejas de que algunos vinos tenían una sequedad muy cercana a la amargura. Pero, igualmente, había que evitar lo contra-

\footnotetext{
29 Russell A. Christian, Sherry, F.H. Doulton and Co., London, 1881, p. 29.

30 Henry Vizetelly, Facts about Sherry, Ward, Lock and Tyler, London, 1876, p. 50.

31 A.H.O.C. ${ }^{\text {a: }}$ Correspondencia Comercial, legajo 125, Londres, 8-VI-1824.

32 A.H.S.J.: Correspondencia Comercial, libro C, Londres, 21-VI-1831.
} 
rio, por lo que los vinos pálidos debían contener el dulce en la cantidad precisa, sin prodigarlo haciéndole perder a la combinación, como acontece algunas veces, su carácter de vino seco, viniendo a ser abocado ${ }^{33}$. Esta advertencia de criadores de vino de Jerez indica la preferencia por el gusto seco y semiseco en los vinos pálidos de Jerez en el mercado británico. Los paladares extremos de los vinos pálidos (muy seco y semidulce) también se pedían y preparaban, pero eran de menor consumo en el Reino Unido.

En cuanto a que los vinos pálidos y el vino Fino eran el siglo XIX dos tipos diferentes de vino de Jerez son muy precisas las palabras que Pedro Domecq escribió en 1845: Últimamente la gente parece estar muy equivocada a la hora de tomar el color del vino como una prueba de calidad. El buen Sherry es generalmente de un color pajizo, que con la edad se hace dorado. Un Sherry viejo no puede ser pálido, aunque un Sherry fino sí puede ser pálido, pero ni inmaduro ni aguado; y la gente debería saber que los peores Sherries que se exportan desde España son generalmente los vinos pálidos... ${ }^{34}$ Domecq estableció aquí perfectamente la diferencia entre el tipo Fino y los vinos pálidos de Jerez. Y en el Reino Unido la tendencia entre la segunda y la sexta décadas del siglo XIX fue a favor de vinos pálidos, principalmente de los dos sabores señalados: seco y semiseco. El gusto por el vino Fino, de paladar seco y muy seco, fue tomando consideración entre los consumidores paulatinamente, y durante mucho tiempo se continuó preparándolo para la exportación.

La información de Pedro Domecq y su opinión experta de que los pálidos eran los peores sherries que se exportaban al Reino Unido lleva a plantearse quiénes eran los consumidores británicos de estos vinos de Jerez. Hay opiniones encontradas sobre si sólo podían consumir jerez los miembros de los sectores sociales con mayor poder adquisitivo o si también les era posible a los de amplias capas de la población. En la época se decía que pese a la reducción de los derechos arancelarios efectuada en el año 1825 , los precios de los vinos seguían siendo tan altos que las im-

33 Revista Vinícola Jerezana, 10-III-1867.

${ }^{34}$ Charles Tovey, Wine and Wine Countries, $2^{\text {nd }}$ ed., Whittaker, London, 1877 , pp. 169-170. Katharina Groëssl, «Tipos de sherry en época Victoriana», en Javier Maldonado Rosso y Alberto Ramos Santana (Eds.), Actas del I Encuentro de Historiadores de la Vitivinicultura Española, Ayuntamiento de El Puerto de Santa María, 2000, pp. 113-126, pp. 115-116, incluye otra carta de Domecq del año 1854 en la que éste se refiere a la manía sobre los vinos pálidos de Jerez. 
portaciones se limitaban a los vinos de mejor calidad, «que consecuentemente sólo estaban al alcance de la clase acomodada» ${ }^{35}$. Sin embargo, otros autores sostienen que los oportos no eran vinos de consumo puramente aristocrático, sino que su consumo estaba muy extendido en las tabernas de las grandes ciudades inglesas ${ }^{36}$. Pan-Montojo expone al respecto que varias fuentes parlamentarias británicas de mediados de la década de los años cincuenta del siglo XIX señalaron que «la caída del vino de Oporto estaba relacionada con el menor consumo aristócrata, y el auge del jerez con el avance de las clases medias, que habían introducido la costumbre de beber vino blanco en las comidas en lugar del tinto de sobremesa» ${ }^{37}$. Lo que podemos señalar es que de la correspondencia comercial de las principales casas exportadoras jerezanas se desprende que había demanda de vinos de Jerez ordinarios y de calidad. Durante toda la primera mitad del siglo XIX los agentes en el Reino Unido de las casas exportadoras jerezanas solicitaban vinos de bajos precios, para los que decían que tenían muchos clientes. La veracidad de estos argumentos debe ponderarse teniendo en cuenta el interés de los comitentes por lograr un mayor margen de beneficio en este comercio. No obstante, parece que la tendencia a favor del vino pálido de Jerez estaba asociada, al menos en parte, a su menor precio.

Los vinos pálidos más vendidos en el Reino Unido no formaban parte de la clasificación numérica del 1 al 10. Eran vinos que se conocían por su tipo y por los precios, y no se recogían en las tarifas que acordaban periódicamente los exportadores jerezanos. Los precios de estos vinos eran de 22 a 26 libras la bota de 500 litros en los años de 1826 en adelante; esto, es, de 5 a 9 libras más baratos que la bota del sherry N. ${ }^{\circ} 1^{38}$. Los agentes en el Reino Unido de las casas exportadoras jerezanas pedían que se les enviasen vinos pálidos de esta clase, para los que había una considerable demanda. Algunas casas exportadoras llegaron a embarcar a los precios de 16 y 18 libras la bota, y aún pretendían que se redujesen más, pues informaban en 1829 que el vino llamado Bronti que viene de la Sicilia ofrece mucha competencia a los vinos inferiores de esa vendiendose a

35 James Simpson, La producción de..., p. 184.

36 François Guichard et Philippe Roudié, Vins, vignerons et coopérateurs de Bordeaux et de Porto. Études Viticoles Franco-Portugaises, T. 1., Editions du Centre National de la Recherche Scientifique, Paris, 1985, p. 13.

37 Juan Pan-Montojo, op. cit., pp. 78-79.

38 Javier Maldonado Rosso, La formación del capitalismo..., pp. 318-324. 
libras 12 y libras $13^{39}$. En 1834 se vendían vinos de Jerez a 11 libras y en 1835 se exportaron vinos al precio de 8 libras $^{40}$. Teniendo en cuenta que el N. ${ }^{\circ} 1$ se vendía regularmente a 2 o 3 libras menos de su precio oficial de 31 libras, en 1835 se estaban vendiendo vinos ordinarios de Jerez a 20 libras menos que el más barato de los vinos de la clasificación pública establecida ${ }^{41}$. Hay que considerar que también los tipos golden y brown se vieron afectados por la demanda de vinos baratos, aunque con posterioridad al tipo pale.

La tendencia de los consumidores británicos hacia el jerez pálido manifiesta un cambio de gusto a favor de vinos semisecos y secos que años más tarde se extendió también a vinos de otras zonas, aunque con desigual resultado. Fue el caso del vino de Oporto, donde se desarrolló un debate entre los exportadores acerca de la producción de oporto seco. Fue el barón Forrester - comerciante británico establecido en Oporto- quien planteó la conveniencia de volver a la producción de vino seco, que consideraba que era el legítimo oporto y del que creía que obtendría mayores cuotas de consumo en el mercado inglés que el oporto semidulce y dulce. Forrester basaba su propuesta en el hecho de que si bien en los años veinte tuvieron la preferencia los vinos mais fortes encorpados, doces y tintos, en la década de los años treinta el gusto británico mudó hacia vinhos louros, pouco encorpados e con muita velhice, y estaba convencido de que esa tendencia continuaba a mediados de los años cincuenta del siglo XIX, cuando él se expresaba en tales términos, y que continuaría desarrollándose. En esos años cincuenta se volvió a producir Porto Branco (como ya se había hecho en el siglo XVIII), probablemente con la intención de participar en la demanda británica de vinos pálidos, ligeros y de buen paladar que indicaban los agentes comerciales ${ }^{42}$. Que la tendencia era esa

39 A.H.S.J-: Correspondencia Comercial, 20-XI-1829

40 Ibidem, 11-VIII-1834 y 10-I-1835.

${ }^{41}$ Conceiçâo Andrade Martins, Memoria do vino do Porto, Instituto de Ciências Sociais da Universidade de Lisboa, 1990, p. 91, constata por otras fuentes que en las primeras décadas del siglo XIX «... os ingleses passaram a preferir vinhos mais baratos e mais leves, como no caso dos espanhóis».

42 José-James Forrester (barao de Forrester), A verdadera causa da crise commercial no Porto, Typ. Gumercial, Porto, 1859, segunda ediçâo, p. 12; Gaspar Martins Pereira, O Douro. O vinho, a vinha e a regiâo de Pombal a Joao Franco, CENPA, Porto, 1990, pp. 70-71; y Conceiçâo Andrade Martins, op. cit., pp. 96 y 140 (nota 53), que señala que un decreto de 11-X-1852 obligaba a los comerciantes a exportar vinos de Oporto de segunda calidad para competir con los españoles. 
y que así continuó para los vinos de Jerez está constatado en la década de los años sesenta. La Revista Vinícola Jerezana decía a principios del año 1866: los datos recogidos por los que tratan en el negocio demuestran que no solo son bien recibidos los vinos de estilo fino, sino que obtienen preferencia; llevada a tal extremo que la misma Manzanilla de Sanlúcar y algunos vinos de Montilla han hecho muchas veces ventaja a los de Jerez en el mercado de Londres ${ }^{43}$.

\section{Consecuencias de los cambios de gusto y consumo en el mercado de origen}

Estos cambios de gusto y de consumo en el Reino Unido respecto a los vinos de Jerez tuvieron unas consecuencias muy importantes en esta zona vitivinícola ${ }^{44}$, al igual que en Burdeos ${ }^{45}$, Oporto ${ }^{46}$, Madeira ${ }^{47}$, Canarias $^{48}$, posteriormente Marsala ${ }^{49}$, y, en menor medida, en otras regiones. El primer cambio, el de la revolución inglesa de las bebidas, dio lugar a que las tradicionales viticulturas de exportación de estas zonas se transforma-

43 Revista Vinícola Jerezana, 15-I-1866.

44 Donald Robert Abbot, The Spanish and the sherry trade: Jerez de la Frontera in the eigtheenth century, U.M.I., Michigan; y Javier Maldonado Rosso, La formación del capitalismo...

${ }^{45}$ Henri Enjalbert, op. cit.; René Pijassou, op. cit.;

46 Gaspar Martins Pereira, op. cit.; Francisco Ribeiro da Silva, «Os mercadores ingleses e a Companhia Gerald a Agricultura das Vinhas do Alto Douro 81756-1800)», en Os vinhos licorosos e a história, CEHA, Funcha,, 1998, pp. 267-284; Norman R. Bennet, «The Golden Age of the Port Wine System, 1781-1807», The International History Review, XII, 2, May 1990, pp. 221-248; y Antonio Barros Cardoso, Baco \& Hermes. O Porto e o comércio interno e externo des vinhos do Douro (177-1756), 2 vols., GEHVID, Porto.

47 Alain Huetz de Lemps, Le vin de Madère, Editions Glénat, Grenoble, 1989; y Alberto Vieira, «A vinha e o vinho na Madeira nos séculos XVII-XVIII», en Os vinhos licorosos e a história, Centro de Estudos de História do Atlântico, Funchal, pp. 99-119.

48 Antonio Béthencourt Massieu, Canarias e Inglaterra: el comercio de vinos (16501800), Cabildo Insular de Gran Canaria, 1991; Agustín Guimerá Ravina, Burguesía extranjera y comercio atlántico. La empresa comercial irlandesa en Canarias (1703-1771), Gobierno de Canarias, Santa Cruz de Tenerife, 1985; y Antonio Macías Hernández, «La viticultura canaria. Orto y ocaso, c. 1500-1850», en Javier Maldonado Rosso y Alberto Ramos Santana (Eds.), Actas del I Encuentro de Historiadores de la Vitivinicultura Española, Ayuntamiento de El Puerto de Santa María, 2000, pp. 319-343.

49 Rosario Lentini, «Un vino inglese nel cuore del Mediterraneo: origini e caratteristiche del Marsala», en Douro. Estudos e Documentos, n. ${ }^{\circ} 21$, 2006, pp. 175-182. 
sen en modernas agroindustrias vinateras, cada una de ellas con sus características propias y a lo largo de un proceso que se extendió en el tiempo de manera variable. En el Marco del Jerez el proceso de modernización se retrasó unas décadas debido a la oposición frontal de los grandes cosecheros de vinos de la ciudad de Jerez de la Frontera, que preferían exportar los mostos y vinos en claro de la cosecha en los meses de octubre/ noviembre y de marzo/abril, respectivamente, a fin de realizar cuanto antes las ventas de sus cosechas. En su disputa con los comerciantes-exportadores por el control del mercado local de vinos recurrieron al proteccionismo y se constituyeron formalmente en gremio. En las ordenanzas que redactaron en 1733 y les fueron aprobadas por el Consejo de Castilla establecieron una regulación del mercado de vinos a la medida de sus intereses: se prohibía el almacenado de vinos a quienes no fuesen cosecheros y se establecían precios mínimos de venta de los mostos y vinos en claro de la cosecha, bajo multa a los infractores, entre otras restricciones ${ }^{50}$. El resultado de esta regulación proteccionista fue el desplazamiento de la crianza y preparación de los vinos al gusto inglés al mercado británico. Era en varias ciudades británicas donde los mostos y vinos en claro de Jerez, El Puerto de Santa María y otras localidades de la zona se dejaban madurar durante unos meses y se combinaban con otros para prepararlos al gusto de los consumidores. Las disputas entre el Gremio de Cosecheros de Vinos de Jerez y los comerciantes prosiguieron durante las siguientes décadas. En los años sesenta del siglo XVIII los exportadores hacían caso omiso de las prohibiciones de las ordenanzas: constituyeron almacenados y preparaban y embarcaban vinos al gusto británico; y en 1772 un grupo compuesto por exportadores que eran también propietarios de viñedos y por cosecheros de mediano tamaño, encabezado por Juan Haurie, dio el paso definitivo y planteó un pleito ante en Consejo de Castilla pidiendo la supresión del Gremio de Vinatería de Jerez por considerar que era un obstáculo al libre comercio y al desarrollo de la vinatería de la zona, puesto que impedía que el valor añadido que se incorporaba a los vinos envejecidos y preparados al gusto de los consumidores se crease en el mercado de origen. El pleito, que duró años, fue resuelto a favor del Gremio de Vinatería de Jerez, pero ante la dificultad de suprimirlo, el Consejo de Castilla dictó varias disposiciones durante su transcurso a favor del estableci-

50 M. Pan Ferguson, La vendimia y sus problemas en el siglo XVIII, Jerez; Donald Robert Abbot, op. cit., pp. 272-275; y Javier Maldonado Rosso, La formación del capitalismo..., pp. 86-93. 
miento de almacenados y la entrada en la ciudad de vinos de otras zonas para mezclarlos con los de Jerez y prepararlos al gusto inglés; de tal manera que los gobiernos reformistas de Carlos III dieron cobertura legal a las prácticas enológicas y comerciales que estaban llevando a cabo los exportadores.

De hecho y de derecho se fueron poniendo las bases del nuevo sistema de la vitivinicultura jerezana. Se definió el tipo de empresa exportadora como una entidad que integraba todo el proceso de producción y cambio, esto es, el agrícola - como propietaria de viñedos-, el industrial - como propietaria de bodegas de envejecimiento - y el comercial - como vendedora de sus vinos a través de agencias en los mercados consumidores - . Se trataba de un nuevo tipo de empresa que sustituía a la anterior de carácter únicamente comercial o, como máximo, agro-comercial, propia de viticultura de exportación. El envejecimiento de los vinos generó la necesidad de grandes bodegas, y surgió así la nueva arquitectura bodeguera de la zona, de estilo neoclásico. Se desarrolló un nuevo método de envejecimiento de los vinos, denominado de criaderas y soleras, mediante el cual se acorta el proceso de crianza y se consigue la homogeneización de los tipos con independencia de las características de los vinos nuevos de cada cosecha. El envejecimiento de los vinos permitía su exportación a lo largo de todo el año, por lo cual se acabó con la comercialización estacional anterior de los mostos en otoño y de los vinos en claro en primavera. Los precios de los vinos se liberalizaron y el comercio pasivo que practicaban los cosecheros (consistente en esperar a que los comerciantes fuesen a comprarles sus cosechas) se transformó en el comercio activo que pusieron en práctica las casas exportadoras a través del sistema de agencias. En pocos años, la producción y exportación de vinos de Jerez creció de manera muy considerable: de alrededor de unas 4.000 botas de 500 litros a principios de los años setenta del siglo XVIII (producidas en Jerez y El Puerto de Santa María) se pasó a 12.437 botas en el año 1823. La transformación de la actividad vitivinícola fue radical y sus consecuencias económicas, sociales, etc. importantísimas $^{51}$.

Por su parte, el cambio de gusto a favor de los vinos pálidos, ligeros $y$ de buen paladar operado a partir de la segunda o tercera década del siglo XIX tuvo consecuencias enológicas y económicas, pero no sistémi-

51 Javier Maldonado Rosso, La formación del capitalismo..., pp. 393-396. 
cas. El nuevo modelo agro-industrial vinatero continuó desarrollándose, aunque el ramo de las empresas almacenistas (que actuaban como auxiliares de las casas exportadoras) disminuyó considerablemente, no sólo por el mayor empleo de vinos jóvenes, sino también por la introducción de vinos ordinarios más baratos de otras zonas vitivinícolas (Condado de Huelva, Aljarafe sevillano, etc.) así como porque probablemente su número fuese excesivo. Las consecuencias económicas inmediatas de los bajos precios de los vinos pálidos corrientes en la facturación de las empresas exportadoras y, lo que es más importante, en los beneficios no son bien conocidas, pues sólo contamos con la historia de la empresa González Byass realizada por Montañés Primicia, cuya actividad propiamente agroindustrial comienza en los años en los que este estudio acaba ${ }^{52}$. No obstante, es indicativo de que el factor de compensación de los menores márgenes de ganancia de los pálidos corrientes y otros tipos de bajos precios fue el notable incremento de las exportaciones de vino de Jerez al Reino Unido a partir los años veinte del siglo XIX. Pero nos estamos refiriendo a grandes empresas exportadoras jerezanas. Muchas otras medianas y pequeñas casas exportadoras cesaron su actividad antes de mediados de la centuria porque no alcanzaban el nivel mínimo de ventas que les permitiese un resultado positivo. El cambio de tendencia preocupó desde el principio a las casas exportadoras serias, como señalaba JuanNicolás Bölh de Faber a la central de Duff Gordon en 1822: Mucho me temo que se vaya introduciendo poco a poco en esa el gusto por los vinos blancos finos al estilo de acá, lo que dificultará mucho los embarques y quitará las ganancias que daban las mezclas y el vino de color ${ }^{53}$. La empresa Julián Pemartin y C. ${ }^{a}$ se resistía a embarcar vinos pálidos de bajo precio, pues decía en 1832 que siendo tan poca la ganancia estaba cerca la pérdida; pero en ocasiones exportaron en esas condiciones, incluso ocultando su marca, ante las presiones de su agente y los insuficientes pedidos que recibían de vinos de mayor calidad. Y esa parece que fue la norma en el sector exportador jerezano. Dicho ésto, conviene señalar que la crisis a la que la exportación de sherries de ínfima calidad y adulterados condujo al sector vitivinícola jerezano a partir de los años setenta del siglo XIX no es imputable al cambio de tendencia hacia vinos pálidos se-

52 Enrique Montañés Primicia, La empresa exportadora del jerez. Historia económica de González Byass, 1835-1885, Fundación Manuel-María González Ángel y Universidad de Cádiz, Jerez de la Frontera, 2000.

53 A.H.O.C.: Libro 56, p. 46, El Puerto de Santa María, 6-VIII-1822. 
cos y semisecos, puesto que ni había una necesaria relación causa-efecto al respecto ni las prácticas fraudulentas llevadas a cabo por los especuladores se limitaban a tales tipos de vinos, sino que se extendían a todos, y era en los tipos golden y brown en los que más desapercibidas pasaban las adulteraciones.

La consecuencia enológica de la preferencia por vinos de Jerez pálidos secos y semisecos en el mercado británico a partir de la segunda o tercera década del siglo XIX fue muy notable. La producción de vinos pálidos sólo podía realizarse de dos maneras: empleando como base vinos jóvenes, de la cosecha, que aún no hubiesen adquirido el color que aporta la oxidación con el paso del tiempo, o bien vino Fino, que, como hemos señalado anteriormente, conserva el color pálido natural del vino joven de Jerez gracias a la crianza biológica bajo velo de flor. Una tercera posibilidad consistía en emplear ambos tipos de vinos - Fino y pálido corriente - como base de los vinos pálidos de exportación. Dado que para la preparación de los vinos pálidos de mediana calidad que se exportaban para el Reino Unido era imprescindible la presencia de vino Fino en la composición, como hemos señalado anteriormente, la necesidad de mantener soleras de vino Fino aumentó y ello contribuyó al desarrollo y conocimiento, aunque sólo fuese empírico durante mucho tiempo, de la crianza biológica bajo velo de flor, que como ha puesto de manifiesto Casas Lucas recientemente es un fenómeno de gran complejidad biológica que presenta variantes de intensidad que sin duda tuvieron en esta época que nos ocupa una significativa importancia en la producción y el comercio de los vinos pálidos de Jerez ${ }^{54}$.

La manifestación más significativa de esta consecuencia enológica del cambio de tendencia fue el hecho de que ya en los años treinta del siglo XIX algunas casas exportadoras de la zona comenzaran a elaborar y expedir vinos pálidos de calidad al Reino Unido y otros países, principalmente a Estados Unidos. Duff Gordon distinguía varios tipos en 1837: Superior Pale Sherry, al que calificaba como "Conversation wine», otro Superior old Pale Sherry y el Very superior old Pale Sherry ${ }^{55}$. Posteriormente, González Byass producía el denominado Royal Pale y comenzó a elaborar el Fino Tío Pepe, una de las marcas de vino de Jerez

54 Justo Casas Lucas, La vinificación en Jerez en el siglo XX. Antecedentes, interpretaciones y aportaciones entre 1955 y 1985, Consejería de Agricultura y Pesca de la Junta de Andalucía, Sevilla, 2008, pp. 213-222.

55 Javier Maldonado Rosso, Los inicios del Fino ..., p. 43. 
más conocidas y reputadas ${ }^{56}$. El creciente consumo de vinos secos, ligeros y de paladar natural en el mercado británico conducía consecuentemente al incremento de la producción del vino Fino y a su desarrollo como tipo característico de vino de la zona del jerez. Además de ello, hay que considerar que los vinos de estilo Fino (pálidos corrientes, Fino, Fino-Amontillado y Manzanilla de Sanlúcar) eran los tipos más apreciados y de mayor consumo en los mercados comarcal gaditano-xericiense y regional andaluz.

\section{Conclusiones}

En los siglos XVIII y XIX se produjeron en el Reino Unido dos cambios de gusto y consumo respecto a los vinos de Jerez. La primera mudanza, que tuvo su origen en la llamada revolución inglesa de las bebidas y causas diversas (desabastecimiento relativo de vinos franceses por causas bélicas, inclinación por otros gustos y distinción social), consistió en la preferencia por vinos envejecidos, con cuerpo, alta graduación alcohólica, paladar abocado y color oscuro. Se trataba de vinos de calidad media y alta y de elevados precios (31 a 57 libras/bota), denominados golden y brown sherry, que se consumían como aperitivo y postre por parte de los sectores más acaudalados de la sociedad británica.

El segundo cambio de gusto y hábitos de consumo se inició en los años veinte del siglo XIX y consistió en la preferencia por vinos pálidos, ligeros, de menor graduación alcohólica que los golden y brown, y secos y semisecos. Se trataba, en general, de vinos corrientes de baja calidad y bajos precios (8 a 16 libras/bota), denominados pale sherry, que eran consumidos en las comidas por parte de las ascendientes clases medias británicas ${ }^{57}$. Pero, a diferencia de la primera mudanza, este nuevo tipo de vino de Jerez dio lugar, posteriormente, a otro, el Fino, semejante pero de calidad óptima y precios similares a los golden y brown ${ }^{58}$, denominado por las casas exportadoras jerezanas y portuenses como Superior Pale Sherry, Royal Pale, etc., que las clases altas británicas sumaron (no sustituyeron) a su consumo de los tipos golden y brown.

56 Catarina Groëssl, op. cit., pp. 116-117; y Enrique Montañés Primicia, op. cit., pp. 139-141.

57 Juan Pan-Montojo, op. cit., pp. 78-79.

58 Javier Maldonado Rosso, La formación del capitalismo..., pp. 318-324. 
De este segundo cambio de gusto y consumo, menos conocido hasta ahora que el primero, hay que señalar que comenzó a producirse treinta años antes de lo que se ha venido estimando y que fue resultado de las preferencias de gusto y hábitos de consumo de las ascendientes clases medias así como de las estrategias de los influyentes wine merchants británicos, como pone de manifiesto la correspondencia comercial entre las empresas jerezanas y sus agentes y principales comitentes en el Reino Unido ${ }^{59}$. En cuanto al alcance del consumo en el Reino Unido de los vinos pálidos corrientes y vino Fino respecto al total de los vinos Jerez importados, son muchas las dificultades para medirlo, pues las estadísticas ofrecen los datos agregados de los diferentes tipos de jereces y las fuentes documentales empresariales son insuficientes y parcas al respecto. No obstante, datos disponibles sobre las calidades de los vinos Jerez consumidos en el reino Unido en los años sesenta ${ }^{60}$ y la elaboración en la zona de Oporto de vino blanco (porto Branco), en los años cincuenta, con destino al mercado británico, son indicios de que los vinos pálidos corrientes y el vino Fino constituían un porcentaje considerable, aunque no mayoritario, de los sherries exportados a las Islas Británicas entre la tercera y la quinta décadas del siglo XIX.

Las consecuencias que tuvieron en la zona de producción de los vinos de Jerez (El Puerto de Santa María y Jerez de la Frontera, principalmente) los cambios de gusto y consumo que se dieron en el mercado británico respecto a ellos en los siglos XVIII y XIX fueron decisivas para la vitivinicultura jerezana.

El primero de los cambios de gusto y consumo de los vinos de Jerez en el Reino Unido fue fundamental para la zona de producción, puesto que la demanda de vinos de calidad envejecidos propició la transformación de la vitivinicultura tradicional jerezana en la agroindustria vinatera jerezana moderna. Aunque muy conflictiva, por la frontal oposición de la aristocracia vinatera a cambiar el sistema agro-comercial pasivo y proteccionista en el que basaba su poder, la transformación a un sistema agro-industrial-comercial activo y liberal manifestó en breve tiempo sus ventajas enológicas, económicas y sociales para el marco del Jerez: la

59 Hecho que ya adelantó Juan Pan-Montojo, op. cit., p.78.

60 James Simpson, La producción de..., p. 168, ofrece los siguientes datos sobre los porcentajes de vinos de Jerez que se consumían en el Reino Unido en el año 1865: 20\% de «compuestos bajos y espurios», $40 \%$ de «jerez común, ordinario o medio», $30 \%$ de «buen jerez» y $10 \%$ de «jerez de calidad superior». 
constitución de grandes empresas vitivinícolas, el desarrollo del peculiar sistema de envejecimiento de criaderas y soleras, la generación en origen del valor añadido que hasta entonces tomaban los vinos de la zona en el mercado de destino, el consiguiente incremento del empleo y la creación de riqueza...

Paradójicamente, el segundo cambio de gusto y consumo de los vinos de Jerez en el Reino Unido, que comenzó por la demanda de vinos pálidos corrientes y baratos, dio como resultado final el desarrollo del vino Fino: un vino de calidad y de una marcada singularidad enológica (junto con la Manzanilla), debido a su crianza biológica bajo velo de flor, que con su conocimiento científico al paso del tiempo se ha convertido en el tipo característico de la vinatería jerezana. Un cambio que presagiaba negativas consecuencias económicas para el sector vitivinícola jerezano fue aprovechado enológica y comercialmente por las empresas de la zona de producción.

Indudablemente, los dos cambios de gusto y consumo operados en el mercado británico respecto a los vinos de Jerez tuvieron consecuencias positivas para la vitivinicultura jerezana en los siglos XVIII y XIX: la conformación de la actividad como agroindustria vinatera moderna, primero, y una importante contribución a la crianza biológica bajo velo de flor, después. Dos aportaciones esenciales para la vinatería jerezana contemporánea. 